marks is particularly necessary in international trade to-day where the owner must part with the title or use of his trade mark in order to be able to make it available in another country.

The Congress passed a resolution that the principle of free assignment of trade marks should be adopted by all Convention countries, subject to such limitations as the domestic law of each country requires to prevent deception of the public by the transfer of the mark. A further resolution was passed embodying the principle that persons other than the registered owner may use a trade mark provided that effective control of the use could be ensured by the proprietor, and subject again to such limitations as the domestic law of each country required, so as to prevent the use from deceiving the public.

Several other resolutions of lesser importance dealt with the prevention of unfair trading. When goods have been sold under a trade name which is a word in the vernacular of one of the countries, it may happen that a trader in another country may attempt to market similar goods in that foreign country under the name which is a translation of this word. This practice causes great difficulties and frequently leads to deception of the public. These difficulties would be overcome by the adoption of the principle that the Convention countries will accept and register, in one and the same operation, composite trade marks comprising the mark in the language of origin and its translation into other languages, each element of the composite mark being protected in itself.

These resolutions were supported in principle at the Conference of the International Bar Association held in July in Great Britain.

The adoption of these resolutions at the diplomatic conference of Governments will be a great step forward to the end that problems of international law in regard to industrial property may receive uniform solution in all countries which are party to the International Convention.

R. G. LlOXD

\section{ELEVENTH INTERNATIONAL CONGRESS OF THEORETICAL AND APPLIED LIMNOLOGY}

$\mathrm{T}$

${ }^{*} \mathrm{HE}$ Eleventh International Congress of Theoretical and Applied Limnology held in Belgium was attended by about eighty people representing seventeen different nations; but, despite the small number of participants, the vigorous exchange of opinion between all and sundry was a testimony to its great value. At the opening session, held in the fine assembly hall of the University of Ghent on the evening of August 16, the members were addressed by the president of the International Limnological Association (Dr. Gunnar Alm) and heard a lecture by the chairman of the Organising Committee (Prof. P. van Oye) on "The Beginnings of Limnology in Belgium". The six scientific sessions, at which upwards of forty papers on a wide range of topics were read, were held in the four university towns, Ghent, Brussels, Louvain and Liège, between August 17 and 23. Among many noteworthy contributions special mention may be made of those by Dr. Thomas (Zurich) on the nature of the monthly sediments deposited in certain Swiss lakes, by Dr. C. H. Mortimer (Windermere) on water movements in stratified lakes, by Prof. W. Rodhe (Uppsala) on a method of sampling and analysis of lake waters by ion exchangers, by Dr. M. Lefevre (France) on antagonisms between successive populations of freshwater algæ, by Prof. d'Ancona (Padua) on the changes induced by the environment on the marine plankton in the lagoons of Venice, and by Prof. Lenz (Plon) on problems concerning chironomid ecology, the last in particular leading to a lively discussion.

On the Sunday afternoon a visit was paid to the Congo Museum at Tervuren near Brussels, where the members of the congress were entertained to tea by the Director and his wife. Similar hospitality was afforded us on several other occasions. In the course of the journey from Brussels to Louvain the large centre for fish-culture at Linkebeek was visited under the guidance of the director of applied limnology, Dr. M. Huet, who also led a three-days tour of south-east Belgium during August 24-26, comprising visits to the principal rivers, to the Michel dam, to the thermal establishment at Spa, and to the grottoes at Han. At the concluding session held at Liège on August 23, a committee consisting of Drs. Mortimer, Ohle and Rodhe was appointed to study and coordinate and, if needs be, initiate, new methods for hydrobiological investigation. The next congress will be held in Cambridge during August 1953.

\section{F. E. Fritsch}

\section{AIRCRAFT-LANDING AIDS IN BAD VISIBILITY}

T a meeting held at Birmingham on September 5 of Section A (Mathematics and Physics) of the British Association, Mr. E. S. Calvert presented a paper entitled "Visual Aids for Landing in Bad Visibility, with Particular Reference to the Transition from Instrument to Visual Flight". Mr. Calvert said that during the past five years radio approach aids have been installed at all major airports to enable aircraft to land in conditions of bad visibility or low cloud. By means of these aids a pilot who is adequately trained in instrument-flying can align his aircraft with the runway and bring it down to a height of about $200 \mathrm{ft}$. without seeing the ground. The rest of the approach and landing, however, have to be made visually, and this means that the pilot has to make a rapid transition from instrument to visual flight when near the ground. At $200 \mathrm{ft}$. the aircraft is still about three-quarters of a mile from the end of the runway, and to bridge this gap a pattern of lights about 1,000 yd. long is laid down in the approach area. This pattern must be such that a pilot seeing only a portion of it can determine the aircraft's attitude, position and direction of motion, and the rates at which these are changing. The lights must be suitable for use by day as well as by night, and for this reason have to be of high intensity. The intensities being used at present are of the order of 100,000 candles.

During the radio portion of the approach, the pilot obtains his positional information either by listening to a voice in his earphones, or by looking at a meter on his instrument panel. From this he has to find the heading which will bring him on to the runway, a task which is particularly difficult when there is a cross-wind which varies with height. $\mathrm{He}$ also has to watch his flight instruments and manipulate the controls. His mind is therefore fully occupied when he sees the lights, and transition from instrument to 